\title{
A Demand Chain Design for Chinese Oatmeal Companies
}

\author{
Haitao Wen, Lijing Song \\ Jilin University (P.R China) \\ wenbt@jjlu.edu.cn, slj0617@,botmail.com
}

Received: November 2014

Accepted: January 2015

\section{Abstract:}

Purpose: The purpose of this paper is to provide a demand chain design framework for Chinese small and medium enterprises in the oatmeal industry, to help them blaze a new trail in China's oatmeal market.

Design/methodology/approach: The approach using in the demand chain design is extended Quality Function Development (QFD), which provides a communication tool so that designers can find a way to integrate customers' needs into design chain.

Findings: This paper illustrates an investigation of oatmeal consumed in China, and the result shows 9 factors influencing consumer's purchasing decisions mostly. Then use these factors to design the demand chain, and the most important processes and tasks for the enterprises are come out from the fist and the second House of Quality (HOQ), which are the main part of the design. Finally, a demand chain design is completed.

Research limitations/implications: It is an application of a demand chain design framework in real Chinese oatmeal market, but the data sample is limited. Consumption surveys should have more data sources with more detailed consumer groups. And the design model needs more real-life examples to verify.

Originality/value: A demand chain design framework is presented with being specific to Chinese oatmeal market. It shows a real-life example of demand chain design, and provides the domestic oatmeal companies with an approach to compete in the market. 


\section{Introduction}

As China's economy continues to develop, fast pace of life makes cereal grain foods more and more popular. At the moment, the annual growth rate is between $15 \%-18 \%$, and the entire industry is in a relatively stable development. Thus, oatmeal market is becoming a vast bright market.

\subsection{Background}

The trend of health, wellness and the convenience are offered by oatmeal. Oatmeal will continue to underpin a good performance over the forecast period, along with higher consciousness of health among Chinese consumers.

According to market research firm, AC Nielsen statistics in China, from October 2008 to October 2009 show, the total amount of breakfast cereal consumption including oatmeal was 73,533 tons, and sales of 1.86 billion yuan wherein the oatmeal market rate is $15 \%$. The sale of oatmeal was 10,000 tons in 1999, and it reached 40,000 tons in 2007. By the end of 2009, there were over 300 oatmeal manufacturers in China.

Although oatmeal products industry develops rapidly in China, there are still some problems need to be solved. Oatmeal impressions like "rough", "healthy but not tasty" may still exist in the minds of many consumers.

Overall, the Chinese consumer market remains to be developed oatmeal; it can be started with following points:

- fight for more consumption,

- fight for people to consume more.

To achieve these two points, to meet consumer demand in terms of oatmeal has become a top priority for all enterprises.

\subsection{Competition}

Since the huge market demand impetus, oatmeal industry in China ushered in a new surge of development. News by Euromonitor International (2011) shows that Nestlé retained its lead in 
oatmeal in 2010 with a $28 \%$ share of value sales, while Guilin Sea Mild reaching an $11 \%$ share to give it a ranking of second. As these statistics show, most of market shares are held by some international or big enterprises like Quaker, Nestlé, Gold Roast and Guilin Sea Mild.

Although these big enterprises almost occupy the entire market, huge market potential still makes the domestic oatmeal manufactories try to blaze a new trail in China's oatmeal market and have a finger in the pie. And they are lack of market consciousness and brand consciousness which have big impact on brand image and consumers' buying decision.

\section{Literature Review}

\subsection{Demand Chain Management}

DCM has developed from the supply chain management literature that preceded it, and it has been argued that it is a broader concept than SCM because it emphasizes understanding the customer's demand and the transformation of that understanding into actionable strategies and plans for the whole group of firms involved in the chain (Langabeer \& Rose, 2001). Then development of market-oriented thinking makes more and more scholars begin to focus on DCM. Hilletofth and Ericsson (2007) defined the DCM as "the alignment of demand creation and demand fulfillment processes across functional, organizational and inter-organizational boundaries". Jüttner, Christopher \& Bake (2007) maintain that DCM involves:

- managing the integration between demand and supply processes;

- managing the structure between the integrated processes and customer segments and

- managing the working relationships between marketing and supply chain management.

Therefore, success in forecasting consumer's demand can create a substantial strategic advantage over the completion since the DCM is mainly based on consumer's demand.

In recent years, the domestic scholars also started the research of demand chain management, but compared with the research on the theory of the foreign, domestic research is still in its early stages. Chai Yueting, Tan Wenan, Jia Yan and other scholars conducted a comparative study of the demand chain and supply chain, and thought that the supply chain and demand chain is driven by consumers' demand and it is necessary to see the consumers as the center. Zhang Heping and Taiwan scholar Shen Zhenru and other scholars have further study on the demand chain management, stood by to understand demand chain from the retailer in the supply chain, that dominated by manufacturers price collapse in the original logistics value chain fission, supply chain should be transformed into a consumer oriented. 


\subsection{QFD Method for DCM}

As a consequence, demand chain design is based on a thorough market understanding and has to be managed in such a way as to effectively meet different customer's needs (Jüttner et al., 2007). In this sense, the idea of demand chain design is conceptually similar to new product design through the quality function deployment (QFD) approach.

Quality Function Deployment (QFD) was proposed by Japanese quality expert Shigeru Mizuno and YojiAkao in the late 1960s. Gradually being used by other companies, and widespread with the popularity of the concept of lean production. Therefore, QFD has become a typical representative of the marketing mix product strategy under lean production. After scholars from various countries' in-depth studies, QFD have formed a theory of multi-genre and multiconcept.

The concept of QFD is shown in Figure 1, the items like "plan" and "design" represent the function of quality the right arrow pointed, also refers to systematize the organization, procedure, process which can ensure quality, it is quality assurance system that designed to meet the needs of organization internal management.

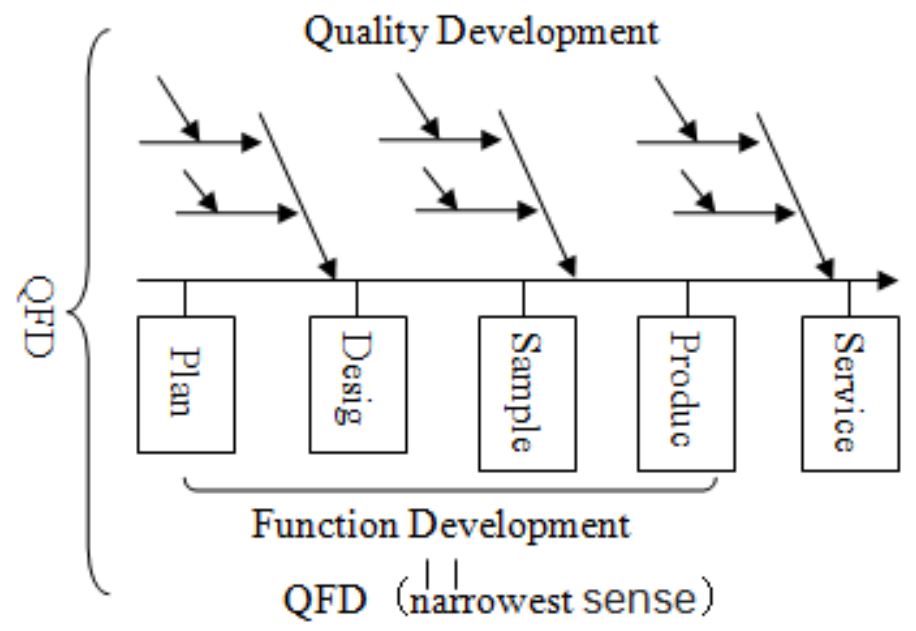

Figure 1. QFD (Wei, 2012)

QFD helps research and development activities closely link to consumers' requirements to enhance the market competition ability of the product, and ensure a successful product development. A preliminary review of the literature has highlighted only a few references where QFD has been associated to DC design. Canever (2006) illustrates a method for how to build a DC by using QFD. 


\section{Consumer Understanding}

\subsection{Data Collection}

The researches of Consumers' behavior for specific product are relatively rare in China, and that of consumers' demand of oatmeal is still blank. So, it is necessary to collect datum about oatmeal consumers for further researches.

As the main consumer group of oatmeal scattering throughout the country, we can't use field investigation. Questionnaire investigation seems to be the first choice. Designing the investigation questionnaire from the perspective of consumer's demand can avoid disjointed situation. So this questionnaire is co-designed by oatmeal customers and authors. The questionnaires are sent to consumers in the supermarkets, as well as 173 questionnaires were recovered, and the efficiency is $90.6 \%$.

\subsection{Chinese Oatmeal Consumer Behavior Analysis}

There are a lot of factors influencing consumer's purchasing decisions. The factors of literature classify and structures are in various ways. Berkowitz, Kerinr, Hartley and Rudelius (1992) proposed that inner and outer factors are two main types of influencing consumers' purchase decision. Brown distinguished three basic categories: personal, psychological and social factors (Brown, 2006), to which Kotler (2001) adds the cultural factors to the independent category. According to research by Stávková, Stejskal and Toufarová (2008), decision making at food purchase acknowledges the complexity of factors determining the purchase: consumers' characteristics and external products' characteristics.

\subsubsection{Consumers' Characteristics}

Oatmeal is a relative new food from western countries, and it is now widely accepted as its convenience and nutritional value. According to the date collected by questionnaire investigation, the higher the consumer's income and education, the more chances to purchase oatmeal. In addition, the number of female consumers is $17.8 \%$ higher than the male consumers as females concern more about the health, and more sensitive to the advertising, sales promotion and packaging. And major consumer groups are under the age of 40, while the major consumer groups' annual incomes are between 10 thousand and 50 thousand yuan. 


\subsubsection{Products' Characteristics}

Characteristics like taste and brand have great influence to consumer's purchase decision. And nutritional value, packing, price, color and retailer also have impact on the decision, while health, function, flavor and availability do a little. Characteristics like sales promotion and marketplace location have no effects on whether consumers purchase oatmeal or not.

\section{Designing and Result}

As the demand chain is a new concept, so the approach technology of implementing demand chain management is not very developed. This makes scholars begin to think:" How to implement Demand Chain?"

Canever illustrates that the QFD applicability can be a method for improving agri-food business and how DC can be brought into reality.

\subsection{House of Quality}

House of Quality is a diagram, resembling a house, used for defining the relationship between customer desires and the firm/product capabilities (Hauser, 1993). It is a part of the Quality Function Deployment (QFD) and it utilizes a planning matrix to relate what the customer wants to how a firm (that produces the products) is going to meet those wants.

$\mathrm{HOQ}$ include six main parts as the Figure 2 shows. "Whats" stands for the main customer requirements, while "Hows" stands for product requirements. The roof is a correlation matrix of "Hows vs. Hows" and the body of the house is a matrix of "Whats vs. Hows". Both of these matrices are filled with indicators of whether the interaction of the specific item is a strong positive, a strong negative, or somewhere in between. And the right side and bottom hold the market competition and the priority. 


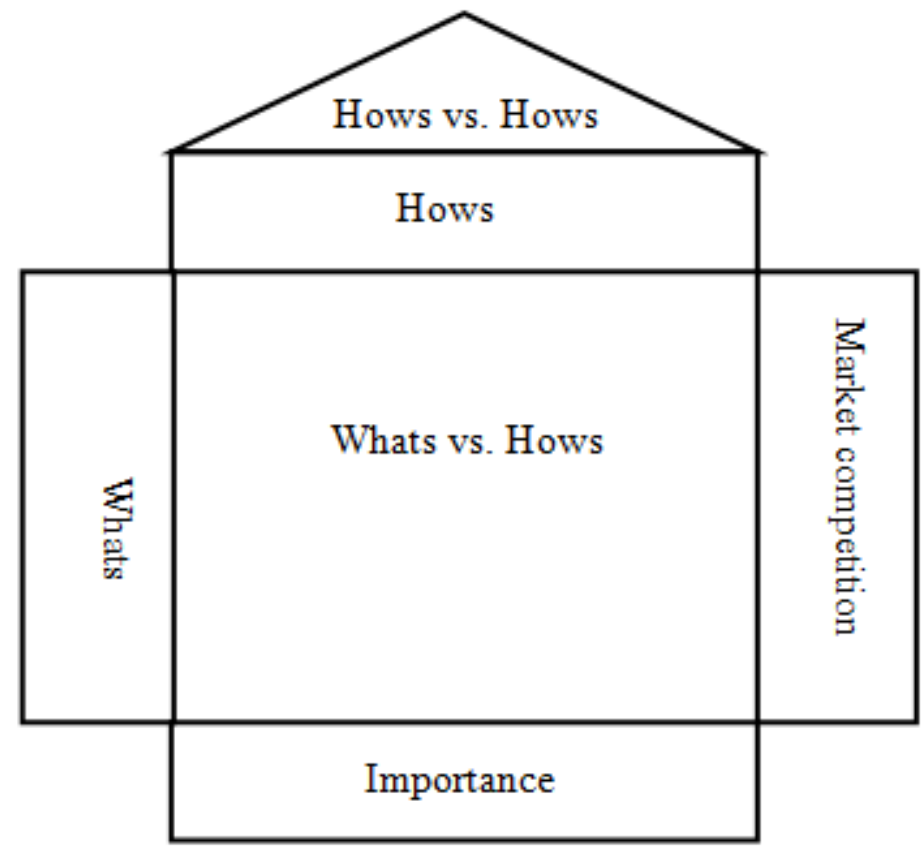

Figure 2. House of quality

\subsection{Design}

\subsubsection{Consumer Demand}

We use KJ method to group consumer's demand into categories, and the result is shown in Table 1.

\begin{tabular}{|c|c|c|}
\hline $\begin{array}{l}\text { The first level of } \\
\text { consumer demand }\end{array}$ & $\begin{array}{l}\text { The second level of } \\
\text { consumer demand }\end{array}$ & $\begin{array}{l}\text { The third level of } \\
\text { consumer demand }\end{array}$ \\
\hline \multirow{9}{*}{ Satisfying oatmeal products } & \multirow{4}{*}{ Sensorial } & flavor \\
\hline & & taste \\
\hline & & color \\
\hline & & package \\
\hline & \multirow{3}{*}{ Services } & retailer \\
\hline & & brand \\
\hline & & availability \\
\hline & \multirow{2}{*}{ Functions } & nutrition \\
\hline & & convenience \\
\hline
\end{tabular}

Table 1. Consumer demand categories

To meet Chinese oatmeal consumer's need, 9 variables were selected from factors that influence oatmeal purchase decision according to the questionnaires. They are flavor, taste, color, package, retailer, brand, availability, nutrition and convenience. The main categories are sensorial services and function, sensorial includes flavor, taste, color and package while services includes retailer, brand and availability, and the rest two are included in functions. 
According to consumer's need, the taste of oatmeal can't be rough and clumpy; the retailers should have a certain credibility and make it always available to get this product.

Importance of consumer demand is very important quantitative indicator in the QFD, which is usually carried out by scoring the demand for each need. Yaahp software helps calculating the importance, and the result is in Table 2.

\begin{tabular}{|c|r|r|}
\hline $\begin{array}{c}\text { The second level of } \\
\text { consumer demand }\end{array}$ & $\begin{array}{r}\text { The third level of } \\
\text { consumer demand }\end{array}$ & The importance \\
\hline \multirow{3}{*}{ Sensorial } & flavor [0.0607] & 0.03337286 \\
\cline { 2 - 3 } & taste [0.6559] & 0.36061382 \\
\cline { 2 - 3 } & color [0.1012] & 0.05563976 \\
\cline { 2 - 3 } & package [0.1822] & 0.10017356 \\
\hline Services & retailer [0.1662] & 0.06117822 \\
\hline [0.3681] & brand [0.7612] & 0.28019772 \\
\hline Functions & availability [0.0726] & 0.02672406 \\
\hline 0.0821$]$ & nutrition [0.6667] & 0.05473607 \\
\hline & convenience [0.3333] & 0.02736393 \\
\hline
\end{tabular}

Table 2. The Result of Yaahp

And to facilitate the next step, rate the importance degrees by $1-5$ and number 5 means very important.

\begin{tabular}{|c|c|r|}
\hline $\begin{array}{c}\text { The second level of } \\
\text { consumer demand }\end{array}$ & $\begin{array}{c}\text { The third level of } \\
\text { consumer demand }\end{array}$ & The importance \\
\hline \multirow{3}{*}{ Sensorial } & flavor & 3 \\
\cline { 2 - 3 } & taste & 5 \\
\cline { 2 - 3 } & color & 4 \\
\cline { 2 - 3 } & package & 4 \\
\hline \multirow{3}{*}{ Services } & retailer & 5 \\
\cline { 2 - 3 } & brand & 3 \\
\cline { 2 - 3 } & availability & 4 \\
\hline \multirow{2}{*}{ Functions } & nutrition & 3 \\
\hline
\end{tabular}

Table 3. The Importance of consumer demand

\subsubsection{HOQ}

The main part of this house of quality ( $\mathrm{HOQ}$ ) is the relationship matrix, which indicates the strength of the relationship between each product feature and each process, then the main task and the important processes. On the roof part, $\odot$ means strong positive, $\circ$ means positive, $x$ means negative and \# means strong negative. And in the main matrix in the house strong relation $=9$ symbolized by $\bullet$, medium $=3$ symbolized by $\circ$, weak $=1$ symbolized by $\triangle$.

From Table 4, we arrived at that Production \& processing management and Brand management hit the highest scores, so these two processes are the most important for Chinese company to fit in the market and win the consumers. And on the roof of the house, we can see planning 
management and brand management influence other processes most, these processes should be taken into account just in case the bad influences. Then, comparison is listed in the right part and the bottom of this house. It shows Chinese companies which are the main object of this paper, Chinese big companies (Chain A) and international companies (Chain B). And it is obvious that Chinese companies' current statuses are quite apart from both consumers' need and the goal came from the matrix.

Then, we use second HOQ to detail the processes and obtain the most important tasks. First, we remove the least important processes- planning management and storage management. Then, list main tasks of other processes as "Hows", while processes are "Whats" (Table 5). So we arrived at that the most important tasks are Health \& safety control and Training sales staff. But Quality \& safety management can influence almost half of other tasks, so it needs to be taken care of.

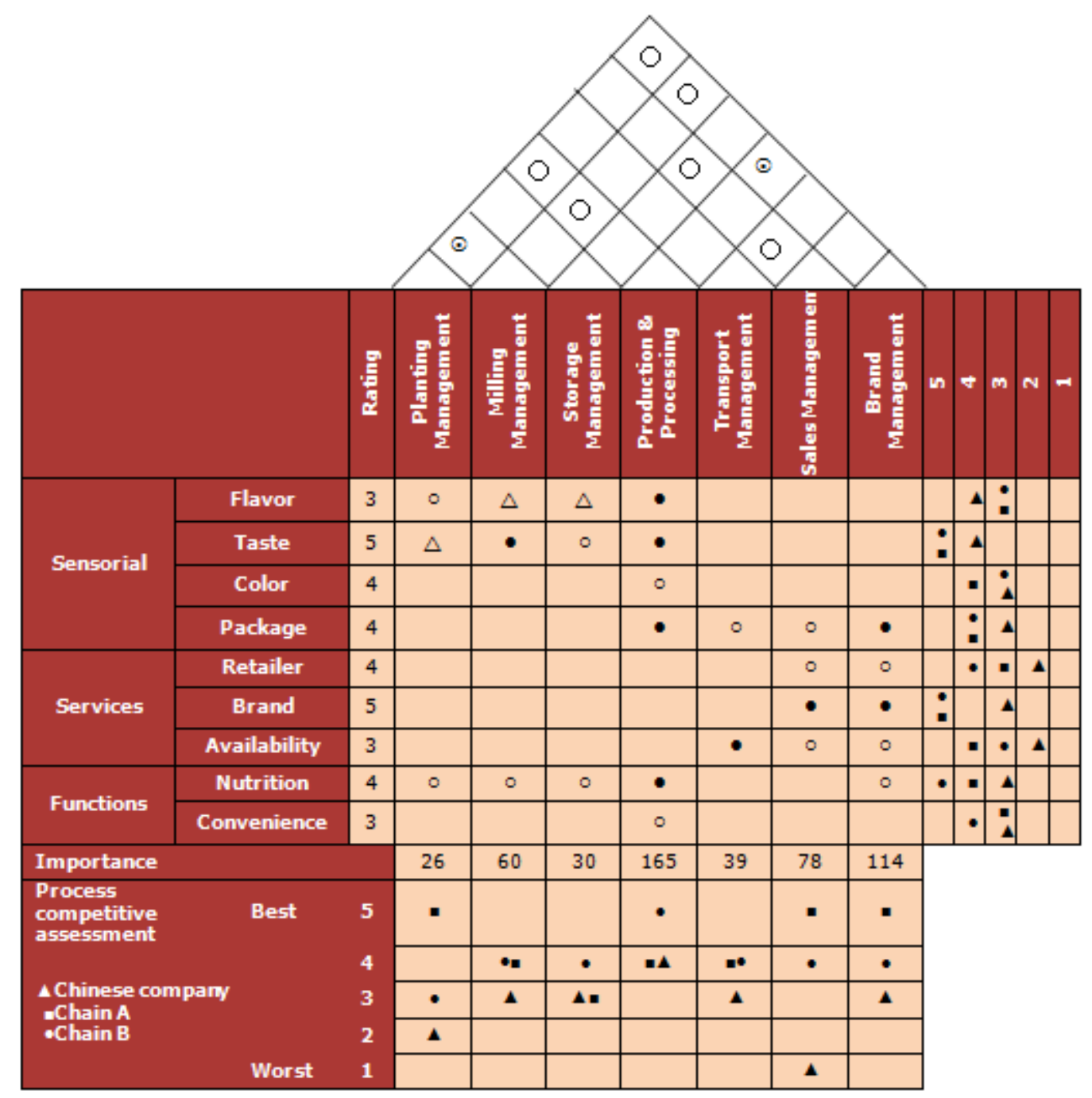

Table 4. The First HOQ 


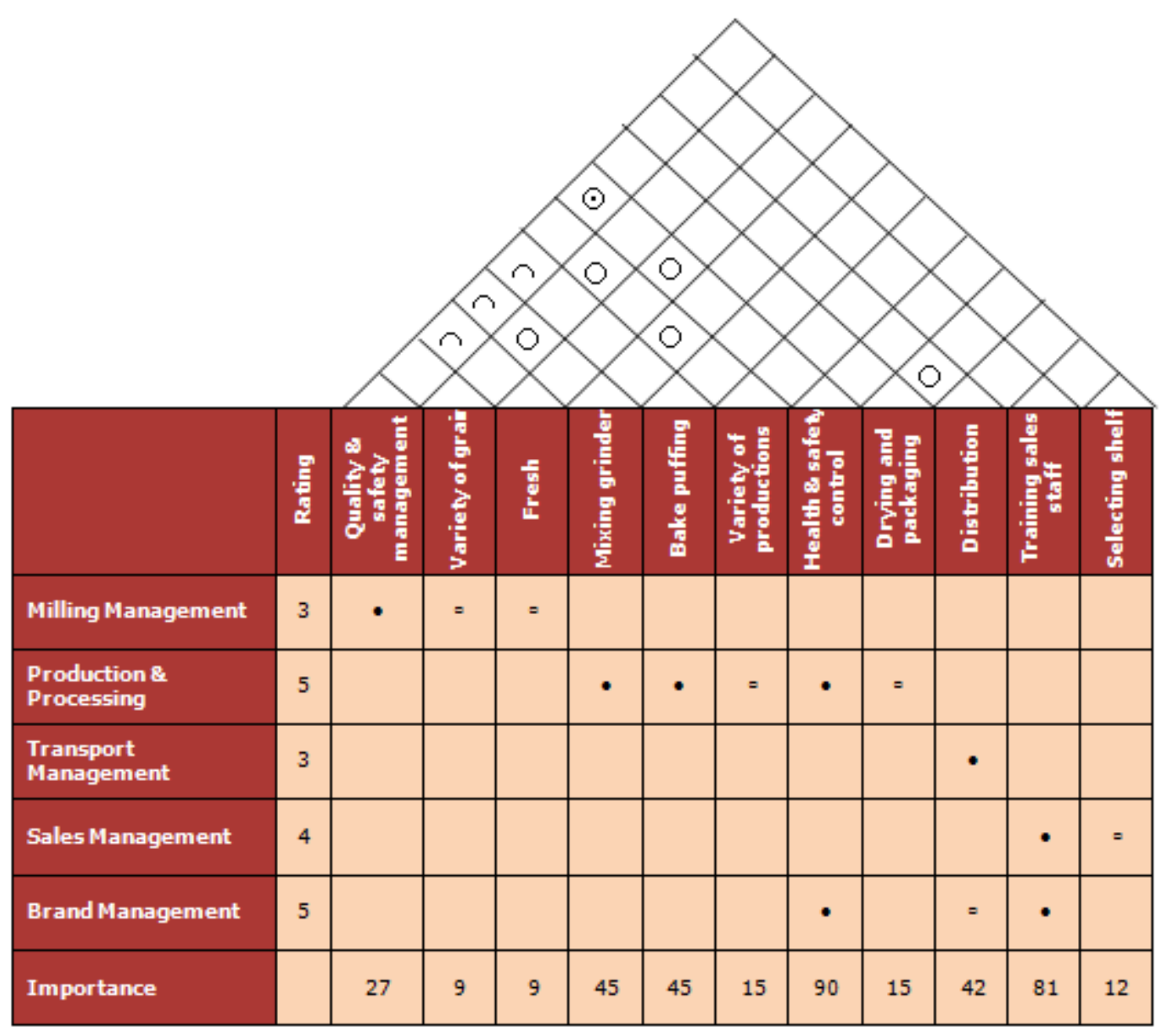

Table 5. The second HOQ

As a consequence, oatmeal companies should put a high value on Production \& processing management and Brand management as these have big impact on fulfilling consumers' demand and win the competition. And Health \& safety control and Training sales staff are the key tasks to start with.

According to the intrinsic characteristics of interdependent transactions, it's more secure establishing suppliers' partnerships with raw materials producers. Choose the right suppliers as partners; establishing co-benefits supplier relationship will be able to supervise raw materials supplying stage. That is, the raw material suppliers can enter the demand chain only after inspection and registration from the core enterprises.

An agreement between retailers and a producer in the form of strategic alliances (Table 6) was seen as the best way of coordinating the interdependencies between these two chain members. The strategic alliance has to leverage the strengths of the two chain members in the long- term through mutual commitment. 


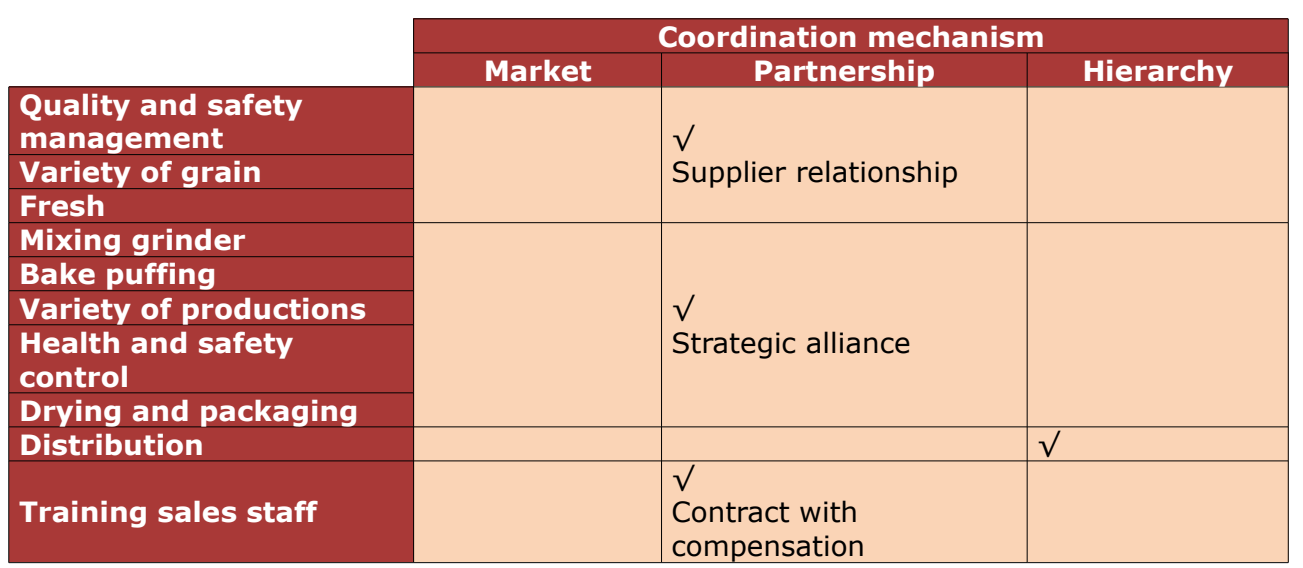

Table 6. Coordination mechanism

It is suggested that the transport is best coordinated through vertical integration, as it has to be quick and accessible to the partners. The integration could be realized by a retailer, retailers or the producers.

Finally, given the importance of labor management at the retailer level for the success of the whole chain, it was decided that the best way to coordinate the sales force through a contractual relationship combined with a variable commission based on the retailer performance. Success of the new demand chain highly depends on the sales force's quality in terms of technical and human skills, and their level of motivation. To ensure highly motivated and skillful employees, the monetary reward has to be adequate but also the relationship of employee-employer has to be friendly and based on mutual commitment.

Enterprises can list several alternative suppliers according to their own circumstances, and then selecting in accordance with four criterions:

- Criterion 1 means guarantee of the quality and safety,

- Criterion 2 means ability to provide a variety of grain flour,

- Criterion 3 means using fresh grain, and

- Criterion 4 means wiliness to collaborate.

If a supplier can meet the entire criterions, then the supplier will be the supplier relationship partner. Willing to collaborate and have the ability to reach some criterions then becomes alternate suppliers. Give up suppliers having no willingness to cooperate. 


\subsection{Analysis and Result}

In the design part, we use 4 steps to complete the demand chain. In the first step, we calculated the importance of each critical demand factor basing on questionnaire data collection. Next, crucial processes and tasks are come from 2 HOQs, which are keys for oatmeal enterprises to win the competition. Then we select different coordination mechanism for different period in the chain, so that the whole chain functions well. Finally, suppliers are chosen based on 4 main criterions.

\subsubsection{Product Management}

SCM plays an important role in DCM as demand creation. And product management reached the highest score as it is the key to fulfill demand toward the market. Using QFD method, we gained a process for consumer-focused product development. Although it is the acting point for any oatmeal company, meeting the taste of Chinese differentiates between winners from others. So it is crucial to develop oatmeal product towards Chinese taste so the company can win the consumers and the competitors. And for the coordination mechanism, partnership like establishing co-benefits supplier relationship or strategic alliances is the wisest choice for Chinese company.

\subsubsection{Brand Management}

Marketing management creates demand, and only with the big demand did the industry grow. Awareness of nutrition value of oatmeal laid the groundwork for the development of oatmeal industry. As brand management is important part of marketing management, it plays an important part of demand creation. Companies can sell more if more consumers know about the brand, like the brand and even trust the brand. It is much more necessary to promote brand in China with the high loyalty of Chinese people. And Training sales staff helps obtain effect getting twice the result with half the effort.

\subsubsection{Market}

Market is the foundation of the whole demand chain; it is both the start and the end of the chain. And market never stays the same, so conducting market research regularly is necessary. It helps the company have a better understanding of target customer, and it is the basis of chain collaboration. So, regular market research is necessary for company to keep pace with changing needs. 


\section{Conclusion}

Demand chin design includes SCM and the marketing management as DCM includes both SCM and marketing. We mainly discussed about the product management and brand management which got the highest scores in HOQ according to oatmeal consumer research in China. The framework of demand chain design was based on a QFD approach using datum gathered from questionnaires. So the "voice of customer" can be built into the chain design, helps the companies meet need of consumer. Then, we select different coordination mechanism for different period in the chain to make whole chain operate more effectively. Finally four criterions are chosen for supplier decision. Analysis and results can help small and medium enterprises who produce oatmeal in China design or rebuild the demand chain so they can gain more consumers and win the competition.

Although the design model used in this paper is quite simple, the demand chain design based on actual market demand is not as smooth as in theory. Nevertheless, China oatmeal demand chain design is a very valuable case as real market demand chain in the background. It provides a viable operation of the program for enterprises who want to improve and implement demand-oriented.

Since the framework of demand chain design is quite new, more work needs to be done to make it fully completed. First, steps of the demand chain design must be validated. Second, expand the criterions of coordination mechanisms and to select members on the demand chain. Finally, design model needs more real-life examples to verify.

\section{Acknowledgments}

The Project Sponsored by the Scientific Research Foundation for the Returned Overseas Chinese Scholars, State Education Ministry.

\section{References}

Berkowitz, E.N., Kerinr, A., Hartley S.W., \& Rudelius, W. (1992). Marketing (3th edition). Boston: Irwin.

Brown, A. (2006). Chapter 6 class notes. Available online in: http://www.udel.edu/alex/chapt6,7-05

Canever, M.D. (2006). From Fork to Farm-Demand Chain Management in the Agro-Food Business. Dissertation of Wageningen University. 
Euromonitor International (2011, October). Breakfast cereals in China: The boom continues. Available online in: http://www.just-food.com/analysis/the-boom-continues id116942.aspx

Hauser, J.R. (1993). How Puritan-Bennet used the house of quality. Sloan Management Review, Spring, 1993, 61-70.

Hilletofth, P., \& Ericsson, D. (2007). Demand chain management: next generation of logistics management. Conradi Research Review, 4(2), 1-17.

Jüttner, U., Christopher, M., \& Baker, S. (2007). Demand chain management-integrating marketing and supply chain management. Industrial Marketing Management, 36(3), 377-392. http://dx.doi.org/10.1016/j.indmarman.2005.10.003

Kotler, P. (2001). Marketing management (10th edition). Upper Saddle River: Prentice Hall.

Langabeer, J., \& Rose, J. (2002). Creating Demand Driven Supply Chains: How To Profit From Demand Chain Management. London: Spiro Press.

Stávková, J., Stejskal, L., \& Toufarová, Z. (2008). Factors influencing consumer behavior. Agric. Econ. - czEch, 54(6), 276-284.

Wei, X. (2012). Quality Function Development-theory and method. Beijing: Science press.

Journal of Industrial Engineering and Management, 2015 (www.jiem.org)

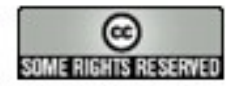

Article's contents are provided on a Attribution-Non Commercial 3.0 Creative commons license. Readers are allowed to copy, distribute and communicate article's contents, provided the author's and Journal of Industrial Engineering and Management's names are included. It must not be used for commercial purposes. To see the complete license contents, please visit http://creativecommons.org/licenses/by-nc/3.0/. 